\title{
Conversas de aprendizagem em museus de ciências: como os deficientes visuais interpretam os materiais educativos do museu de microbiologia?
}

\author{
Alessandra Fernandes Bizerra* \\ Juliana Bettini Verdiani Cizauskas** \\ Glaucia Colli Inglez*** \\ Milene Tino de Franco ${ }^{* \star *}$
}

\begin{abstract}
Resumo
Os processos de divulgação e educação em Ciências vêm tomando grande importância, principalmente a partir do último quarto do século passado. Os museus de ciências, enquanto espaços de educação não formal, têm papel importante na ampliação e refinamento desses processos e, sendo locais abertos à população, são demandados a desenvolver propostas inclusivas. O Museu de Microbiologia do Instituto Butantan desenvolveu uma série de atividades e materiais educativos sobre microrganismos para facilitar a aproximação entre o público deficiente visual e a cultura científica. No presente estudo procurou-se compreender como os visitantes deficientes visuais interpretam os materiais desenvolvidos, verificar qual o entendimento que o uso desses materiais propicia e estudar os tipos de significados que lhes são dados. Pessoas com deficiência visual foram entrevistadas durante a exploração do material com o auxílio de um áudio-guia e as conversas geradas foram analisadas, estabelecendo-se categorias interpretativas. A categoria mais frequente foi a "Estratégica de Uso" $(11,8 \%)$, quando os deficientes visuais manifestavam suas impressões sobre como utilizar o Programa MicroToque. Outras duas categorias, "Afetiva de Prazer" (10,2\%) e "Perceptiva de Identificação" (8,6\%) foram também encontradas. A junção das ferramentas tátil e auditiva foi fundamental para a resolução de problemas e criação de representações visuais, importantes para construção e compreensão de conceitos e facilitando a organização do pensamento teórico. Sugere-se aqui a necessidade de uma organização dos conteúdos que favoreça o estabelecimento de conversas interpretativas conceituais e também a consideração dos conhecimentos prévios de visitantes com deficiência visual na elaboração dos aparatos a eles destinados, o que poderia propiciar maior frequência de outras elaborações conversacionais.
\end{abstract}

Palavras-chave: Deficientes visuais. Museu de Ciências. Materiais para toque. Conversas de aprendizado.

\footnotetext{
* Instituto de Biociências da Universidade de São Paulo, Departamento de Zoologia. São Paulo, Brasil.

** Instituto Butantan, Museu de Microbiologia, São Paulo, Brasil.

*** Instituto Butantan, Museu de Microbiologia, São Paulo, Brasil.

**** Instituto Butantan, Museu de Microbiologia e Laboratório de Imunogenética, São Paulo, Brasil.
} 
Alessandra Fernandes Bizerra - Juliana Bettini Verdiani Cizauskas Glaucia Colli Inglez - Milene Tino de Franco

\section{"Learning-talks in science museums: how a visually impaired person interprets the educational material at the museum of microbiology"}

\section{Abstract}

The processes of science communication and science education became especially important in the last quarter of the last century. Science museums, as non-formal spaces have an important role in amplifying and refining these processes. Being spaces open to the general public will be expected to develop programs that include all of its citizens. The Museum of Microbiology of the Butantan Institute has developed a series of activities and educational materials focusing on microorganisms that were designed to facilitate a closer integration of the visually impaired public with the scientific culture. In the present study, we sought to understand how visually deficient visitors interpreted the materials presented, determine the level of understanding that the use of these materials provided and study the significance attributed to them. Visually impaired visitors were interviewed during their interactions with the materials with the aid of an audio guide, and the talks generated were analyzed within interpretative categories. The most frequent category was "Strategic talk (Use)" (11.8\%), in which the visually deficient visitors gave their opinions concerning the uses of the Micro-Touch Program. Two other categories, "Affective talk (Pleasure)" (10.2\%) and "Perceptual talk (Identification)" (8.6\%) were also established. A combination of tactile and auditory tools was fundamental to solve problems and to the creation of visual representations that are important to constructing and understanding scientific concepts and to facilitate the organization of theoretical thought. We suggest here the necessity of elaborating activities contents that favors the establishment of conceptual talks and considering the previously acquired knowledge of visually impaired visitors during the design of displays, providing higher frequency of other learning talks.

Keywords: Visually impaired person. Science museum. Touching materials. Learning talks.

\section{Introdução}

A educação e a divulgação em ciências são instrumentos importantes que possibilitam aos cidadãos o maior exercício de seus direitos e o enfrentamento das responsabilidades que a sociedade lhes impõe, adquirindo condições de discernir entre os riscos e os benefícios que a Ciência e a Tecnologia propiciam. Nesse cenário, ações educativas e comunicacionais são preocupações constantes e antigas dos museus e centros de ciências que, como espaços abertos à população, devem ter propostas inclusivas. Entretanto, o atendimento voltado a todos os seus públicos ainda está longe de ser efetivado. Pessoas com necessidades especiais, por exemplo, ainda buscam maior acessibilidade a ações educativas específicas, o que motiva os museus a realizarem uma mudança efetiva em sua comunicação (RIBEIRO, 2007). 
Conversas de aprendizagem em museus de ciências: como os deficientes visuais interpretam os materiais educativos do museu de microbiologia?

Entre os museus de ciências brasileiros, ainda é pequeno o número de estratégias educativas que garantam seu uso por grande parte de seu público. No caso do público com deficiência visual completa ou com visão subnormal, a comunicação nesses museus é geralmente realizada facilitando-se a acessibilidade física aos objetos por meio do tato, com a elaboração de modelos tridimensionais relacionados às temáticas de cada instituição (como réplicas de animais e plantas, representação de processos de metamorfose de insetos ou aparatos experimentais interativos). Essa elaboração pauta-se na ideia de que, embora fatores pessoais e características físicas do objeto possam facilitar ou dificultar a identificação tátil (MILLAR, 1997), o toque propicia uma compensação da percepção pela visão no processo de significação. Porém, manusear objetos sem dispor de outras coordenadas parece não ser suficiente para uma melhor aproximação do público com conteúdos expostos nos museus.

Com o objetivo de favorecer sua comunicação com o público composto por deficientes visuais, educadores de espaços museais têm procurado promover o uso de outras modalidades sensoriais, fundamentalmente a audição. Falas presenciais ou gravações em áudio desenvolvidas pelos setores educativos destas instituições vêm sendo utilizadas por pessoas cegas e com baixa visão para acessar diferentes ambientes culturais que, como aponta Consuegra Cano (2002), poderiam Ihes ser inoperantes sem esse recurso. Nesse sentido, por meio da percepção auditiva, uma pessoa com deficiência visual poderia formar uma imagem mental, principalmente se esse estímulo atingir também aspectos emocionais (HERNANDEZ SANZ,1993). Porém, a descrição verbal de um objeto terá maior eficiência se estiver acompanhada da percepção através do tato, permitindo melhores reconhecimento, associação e discriminação em posteriores experiências (MILLAR,1997).

É sob esta perspectiva, em relação ao uso conjugado do tato e da audição, que os setores educativos museais têm construído sua ação educativa voltada para cegos e pessoas com baixa visão. A elaboração de aparatos e objetos tridimensionais acompanhados por áudio-guias, embora ainda incipiente, tem aparecido cada vez mais entre os projetos comunicativos e educacionais dos museus de ciências,

Cabe então indagarmos como esse material vem sendo compreendido pelos diferentes públicos dos museus, principalmente aquele a qual foi direcionado, e como se dá o processo de significação desses materiais. Como sugere Vygotski (1997), é necessário superarmos a redução da pessoa com cegueira à falta de visão. Ao refletir sobre o desenvolvimento psicológico na presença da cegueira, Vygotski defende que as funções psicológicas superiores assumem, ao longo do processo, papéis diferentes dos desenvolvidos nos videntes, embora as leis que regem esse processo sejam as mesmas. Ao agirmos sobre o mundo, individual ou coletivamente, direcionamos nossa atividade a algo. Há objetos com os quais interagimos e é a atividade que medeia essa interação (BANNON, 1997). O uso de instrumentos nessa interação confere uma qualidade produtora à ação humana, capaz de transformar, ao mesmo 
tempo, o sujeito e o objeto. A atividade humana é, portanto, considerada como social, instrumental e transformadora do real (PINO, 2005).

Nesse processo de significação do mundo, a ausência da percepção visual pode propiciar diferenças no desenvolvimento psíquico do indivíduo, como a ocorrência de vias alternativas correspondentes à "compensação social da deficiência" de Vigotski. Vale ressaltar que esse processo de compensação não representa simplesmente substituir um sentido por outro ou fortalecer um sentido compensatório, mas sim produzir novos nexos, principalmente em relação à imaginação e à atividade combinatória, fortalecendo a importância da palavra (e não somente da audição e do tato).

Nesse sentido, a equipe educativa do Museu de Microbiologia do Instituto Butantan (São Paulo, Brasil), propôs-se a investigar como pessoas cegas ou com baixa visão interagem com materiais educativos museais sobre microbiologia elaborados com vistas a atender algumas especificidades desse público, lançando mão de recursos táteis e auditivos. Buscou-se ainda compreender quais tipos de conversas de aprendizagem são elaborados a partir da interação com esses materiais e compartilhados dentro de grupos de visitantes cegos.

\section{Abordagem teórico-metodológica}

\section{Referencial teórico}

Com a proposta de caracterizar a construção dos discursos pedagógicos do Museu de Microbiologia e de investigar elementos do processo de apropriação desse discurso pelos públicos visitantes, foi desenvolvido um estudo de caso, que se refere ao entendimento do uso dos materiais de apoio ao deficiente visual produzidos pela equipe educativa do Museu de Microbiologia do Instituto Butantan.

Assim, tendo em vista a questão específica deste estudo de caso, foi escolhido o referencial teórico de Allen (2002). Essa autora, durante pesquisa realizada no museu "Exploratorium" de São Francisco (EUA), desenvolveu uma metodologia para analisar conversas geradas em visitas a espaços museais, entre o público vidente. A pesquisadora estabeleceu categorias interpretativas, denominadas "conversas de aprendizagem", que codificam as expressões verbais de pensamentos, sentimentos e ações, apresentadas a partir de uma abordagem sociocultural. Para Allen, essas conversas constituem-se como evidências de aprendizagem, pois fazem referência ao ato de identificar e compartilhar aquilo que confere sentido para o visitante em um ambiente complexo como o museu.

Nesta perspectiva, os museus também são instituições bastante propícias para o desenvolvimento de processos de aprendizagem pois estão repletos de instrumentos humanos, construídos historicamente e portadores de infor- 
mações, disponíveis às variadas possibilidades de interpretação dos visitantes que estão ali intencionalmente e, geralmente, por vontade própria.

Podemos considerar, portanto, que a análise por categorização das evidências de aprendizagem constitui-se como um método de investigação cuja força está em ressaltar essa diversidade (em riqueza e abundância) de tipos de evidências de aprendizagem que podem ocorrer no contexto museal. Em um ambiente com variadas possibilidades de apreensão da realidade, um método que forneça indícios do "que" e do "quanto" um visitante aprende ao interagir com o discurso expositivo torna-se ferramenta importante para um setor educativo interessado em desenvolver estratégias de educação e comunicação mais eficazes.

Cinco categorias de conversas de aprendizagem para a análise em museus foram propostas por Allen: conversa perceptiva, conversa conceitual, conversa conectiva, conversa estratégica e conversa afetiva.

\section{Conversa Perceptiva}

É aquela que demonstra a atenção dos visitantes aos estímulos que o cercam. Ao nomeá-los, identificá-los ou caracterizá-los, aponta uma evidência de aprendizado. Contém quatro subcategorias:

Identificação: indicação de algo que tenha chamado a atenção.

Nomeação: declaração de nomes dos objetos, microrganismos etc.

Citação: chamada de atenção para textos em placas ou painéis por meio de leitura em voz alta, leitura em Braille ou repetição de áudio.

Caracterização: indicação de algum aspecto concreto ou propriedade dos objetos.

\section{Conversa Conceitual}

Esse tipo de conversa envolve a participação de conceitos explicitados pelo entrevistado, com declarações genuínas obtidas a partir dos elementos expositivos. Engloba também quatro subcategorias:

Inferência Simples: declarações simples ou interpretação de partes da exposição.

Inferência Complexa: explicitação de hipóteses ou generalizações sobre as informações apresentadas.

Previsão: declarações em relação às expectativas ou antecipações sobre o que pode acontecer durante a visita. 
Alessandra Fernandes Bizerra - Juliana Bettini Verdiani Cizauskas Glaucia Colli Inglez - Milene Tino de Franco

Metacognição: reflexões sobre as próprias declarações em relação a conhecimentos prévios ou obtidos durante a visita.

\section{Conversa Conectiva}

Representa algum tipo de conexão entre elementos da exposição com conhecimentos ou experiências anteriores do entrevistado ou do seu cotidiano. Reúne três subcategorias:

Conectiva com a Vida: declarações sobre histórias pessoais, associações ou comparações de elementos encontrados na visita com algo familiar.

Conectiva com o Conhecimento: declarações relacionadas a conhecimentos obtidos anteriormente em outros espaços de educação formal ou não formal.

Conectiva Intraexibição: conversas que demonstram conexões entre elementos encontrados na visita.

\section{Conversa Estratégica}

Refere-se a comentários sobre estratégias de como utilizar a exposição, incluindo como se mover, olhar ou escutar algo durante a visita. Inclui duas subcategorias:

Uso: informações de como utilizar o conteúdo da atividade.

Metaperformance: conversas que apresentam a avaliação feita pelos próprios sujeitos sobre seu desempenho na visita.

\section{Conversa Afetiva}

Nessa categoria, são incluídas declarações relacionadas a algum tipo de reação ou emoção. Podem ser divididas em duas subcategorias: de Prazer ou Desprazer.

Com esse referencial, é possível identificar os principais tipos de conversas elaboradas durante as interações estabelecidas nas ações educativas, que serviriam como "indícios de aprendizagem". Vale relembrar que Allen (2002) não afirma que estas categorias conversacionais determinam a ocorrência do processo de aprendizagem, mas sim que representam evidências de que os indivíduos estabelecem conexões, identificam objetos, constroem hipóteses, entre outras ações que constituem o processo de aprendizagem. 


\section{Objeto de estudo: o Programa MicroToque}

Para entender como se dá a percepção de conteúdos apresentados pelo Museu de Microbiologia por cegos e pessoas com baixa visão, foi desenvolvido um projeto de pesquisa apoiado pela FAPESP e pela Fundação VITAE. Estabeleceu-se uma parceria com o Instituto Dorina Nowill por meio de seus setores educativos, ação fundamental para a escolha dos materiais a serem elaborados.

O Programa de Apoio ao Deficiente Visual - MicroToque é composto por um conjunto de materiais destinados ao público com deficiência visual, que inclui maquetes, modelos tridimensionais de microrganismos, áudios de apoio à visita, além de materiais não considerados nesta investigação: um áudio sobre o Museu e fôlderes em Braille.

A maquete externa possibilita a exploração da parte artística do prédio que abriga o Museu. A maquete interna apresenta suas subdivisões como a Exposição de Longa Duração, o Laboratório, a Praça dos Cientistas e o Auditório, evidenciadas por texturas em relevo. As maquetes foram produzidas com materiais de alta resistência ao toque, coloridos com duas cores contrastantes, de forma a facilitar a visualização por pessoas com baixa visão (Figura 1).

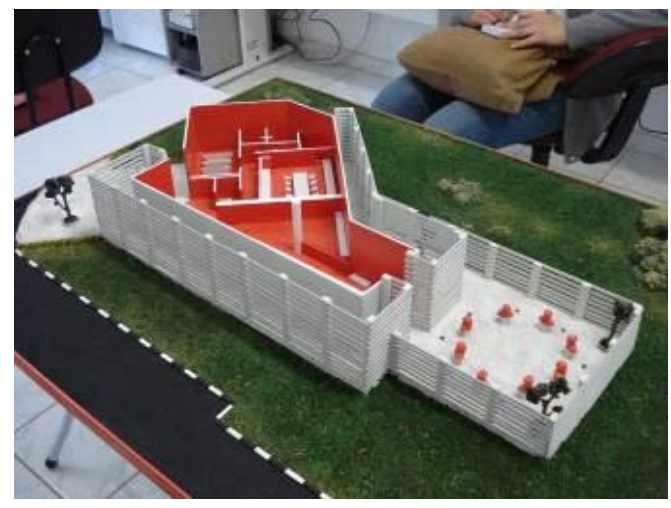

Figura 1 - Maquetes externa e interna do Museu de Microbiologia.

Os modelos tridimensionais do vírus HIV, da bactéria Escherichia coli, do protozoário Trypanossoma cruzie do fungo Penicillium notatum, todos contendo legendas em Braille e em macrocaracteres também foram produzidos com as mesmas características das maquetes e estão representados na Figura 2. 

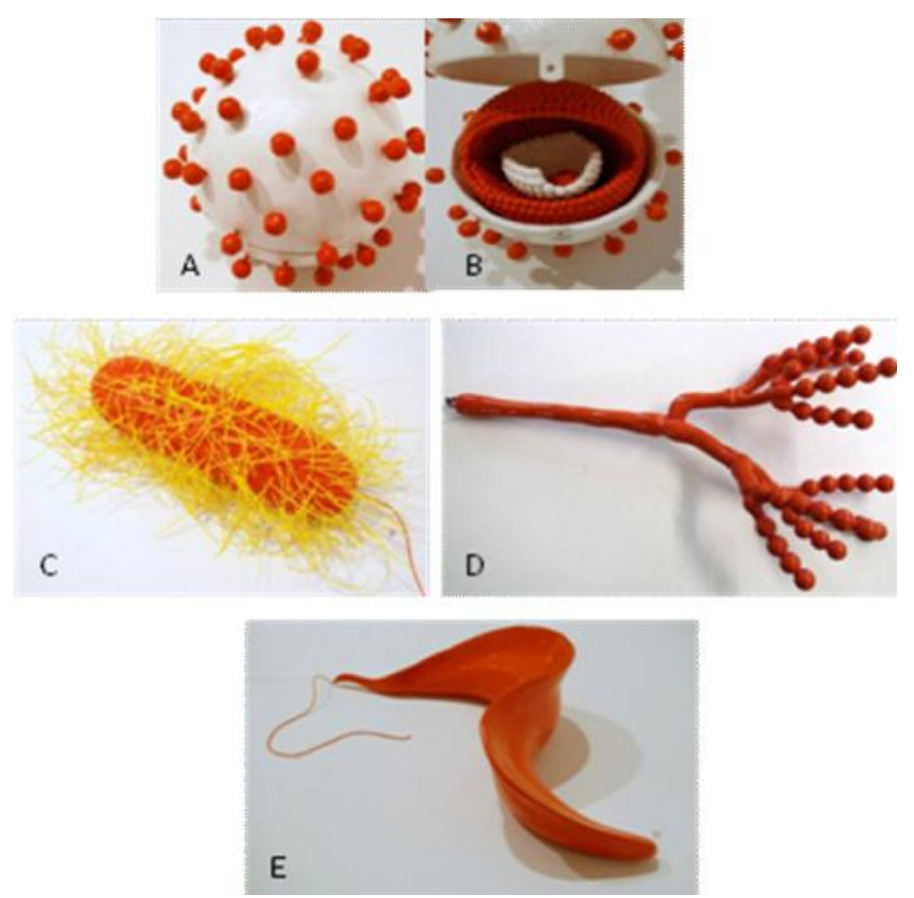

Figura 2 - Modelos de microrganismos do "MicroToque": vírus HIV fechado e aberto (A e B); bactéria Escherichia coli (C); fungo Penicillium notatum (D); protozoário Trypanossoma cruzi (E).

Esses objetos estavam dispostos em um móvel em formato de carrinho (Figura 3), cuja estrutura permite que ele seja aberto, expondo a maquete e transformando suas laterais em mesas para a manipulação dos modelos pelos deficientes visuais. 


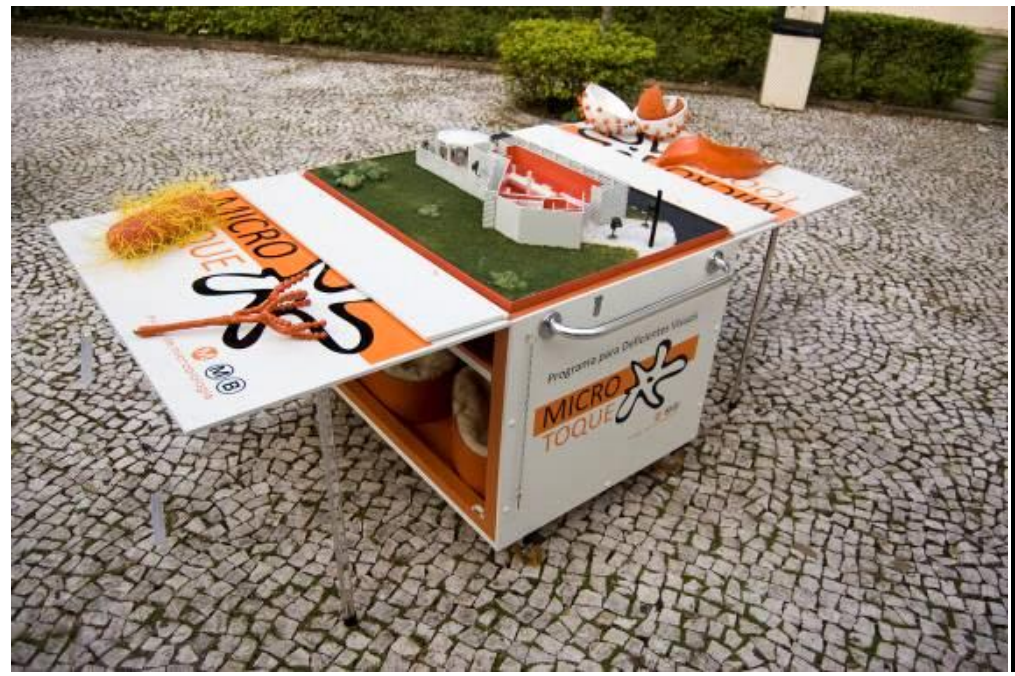

Figura 3 - Carrinho "MicroToque"

Os materiais tridimensionais para toque são acompanhados por um áudio-guia gravado em formato MP3. Esse áudio contém informações sobre o uso da maquete, fornecendo as descrições dos ambientes internos e externos do Museu, o que possibilita ao deficiente visual uma melhor localização nesse espaço físico. Apresenta também um texto introdutório sobre o que são os microrganismos, suas funções, onde podem ser encontrados, entre outros elementos, além de quatro arquivos enfatizando as características específicas de cada um dos microrganismos representados.

Para a elaboração desses materiais, foi utilizado o Modelo Contextual de Aprendizagem, proposto por Falk e Dierking (2000), em que diferentes fatores, relacionados aos contextos pessoal, sociocultural e físico, influenciam a aprendizagem nos museus. Entre os fatores relacionados ao contexto físico, é possível citar a arquitetura do Museu (por isso a necessidade das maquetes), a orientação espacial (necessidade do áudio), o entendimento da mensagem conceitual da exposição e sua contextualização (necessidade do livro falado sobre o Museu e os objetos para toque) e o conteúdo das legendas (legendas em Braille e em macro caracteres). 
Alessandra Fernandes Bizerra - Juliana Bettini Verdiani Cizauskas Glaucia Colli Inglez - Milene Tino de Franco

\section{Coleta de dados}

Duas instituições foram convidadas a participar como parceiros dessa análise: a Fundação Dorina Nowill para Cegos e a Laramara - Associação Brasileira de Assistência ao Deficiente Visual. Foram realizadas entrevistas semiestruturadas, em um número total de sete (sendo que somente três foram aqui consideradas), que ocorreram em momentos separados para os indivíduos das duas instituições (Figura 4).
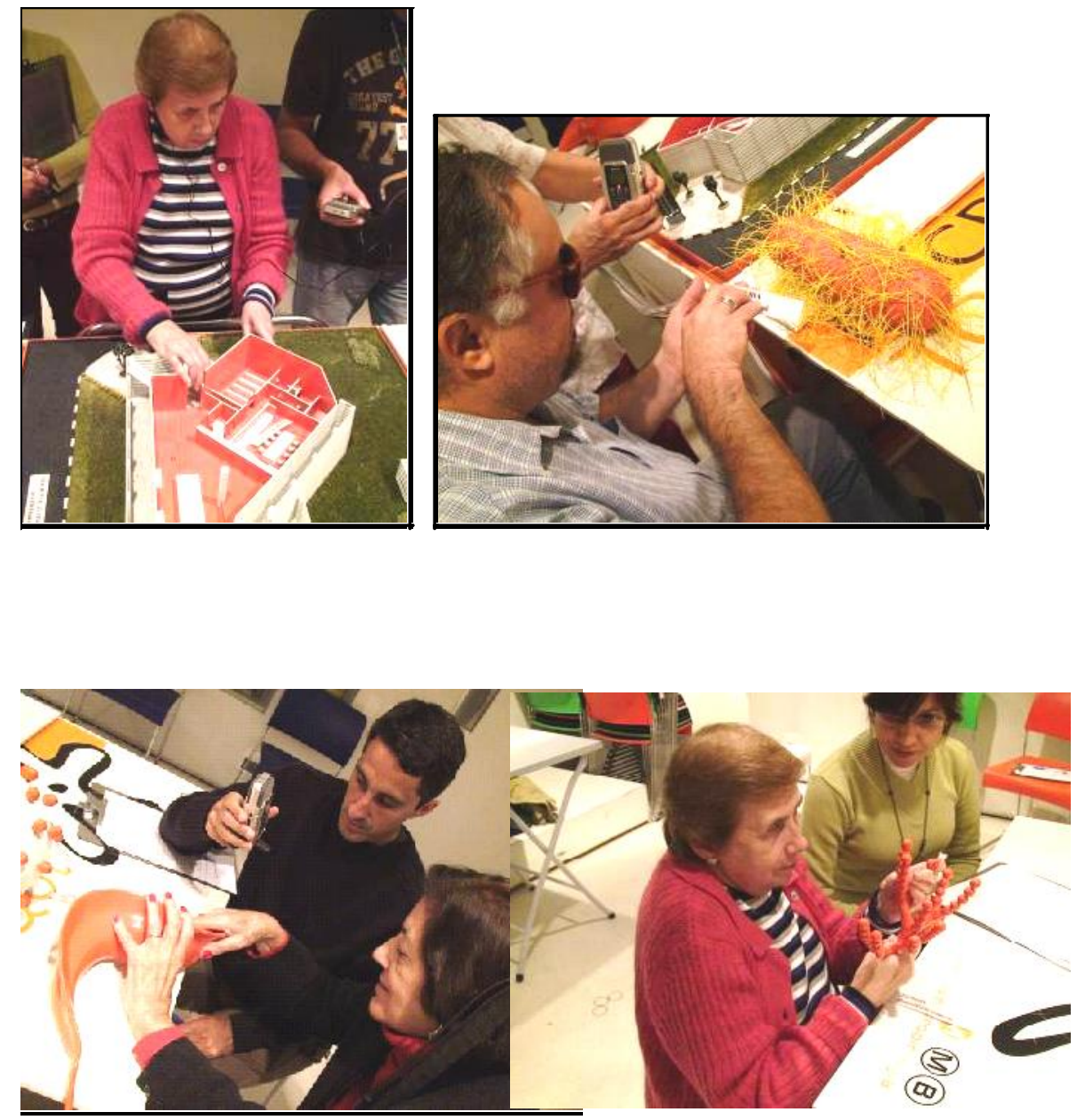

Figura 4 - Sujeitos colaboradores da pesquisa manipulando os elementos do MicroToque durante as entrevistas. 
A exploração do material foi realizada com o auxílio do áudio-guia e cada visitante foi acompanhado por um membro da equipe do Museu. As entrevistas foram registradas em áudio, imagens fotográficas e vídeo. Além disso, foram realizadas anotações de campo.

\section{Resultados e discussão}

As três entrevistas consideradas nesta análise estabeleceram 314 conversas, distribuídas nas 15 categorias de Allen (2002). Observou-se que essa distribuição não se deu ao acaso e que determinadas categorias foram desenvolvidas com maior frequência $\left(X^{2}=53.515 ; p<0,001\right.$; Figura 5).

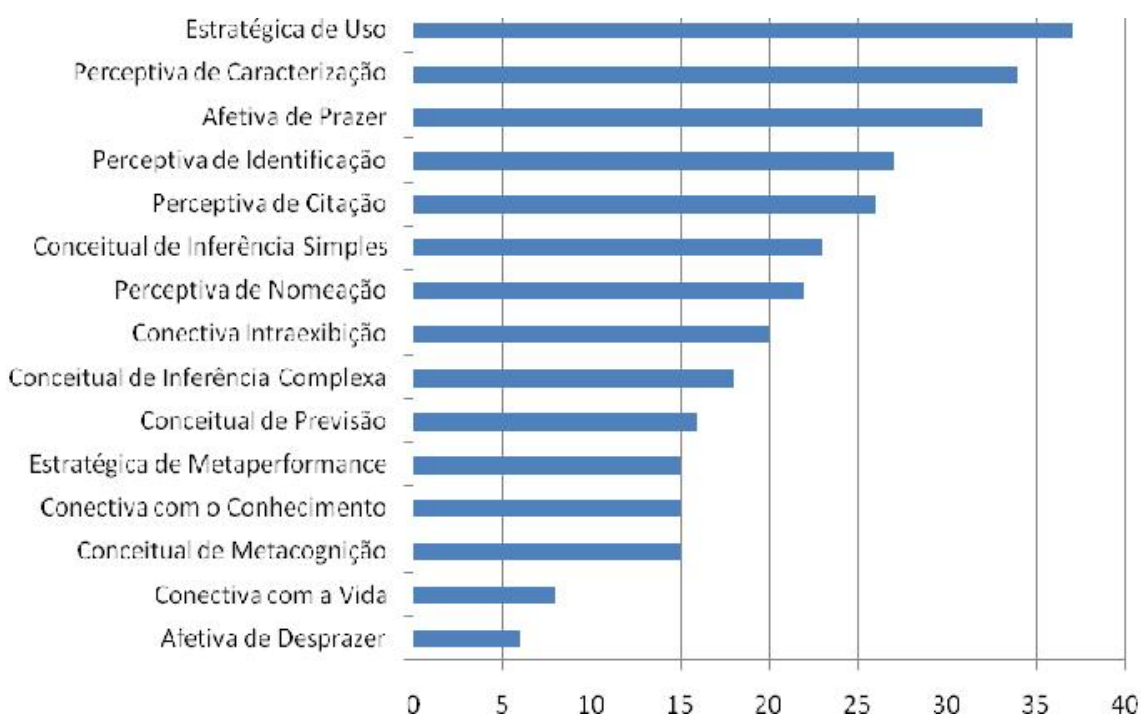

Figura 5 - Número de conversas de aprendizagem desenvolvidas pelos visitantes a partir do Programa de Apoio ao Deficiente Visual, por categoria conversacional $(\mathrm{n}=314)$.

A categoria mais frequente foi a "Estratégica de Uso" (11,8\%). Nesta categoria foram incluídas conversas em que os deficientes visuais manifestavam suas impressões sobre como manipular os objetos tridimensionais, ler as legendas em Braille, utilizar o aparelho transmissor do áudio, além de fornecerem sugestões para aperfeiçoamento do áudio relativo aos objetos tridimensionais. Assim, foram consideradas nesta categoria falas como (em parênteses, a identificação do visitante): 
“Ah! Ele abre?” (relativo a modelo tridimensional) (V01) "Ahan...tá ...então a gente pode pegar a plaquinha, segue a plaquinha..." (relativo às plaquetas em Braille) (V02)

"Deixa eu pegar nele primeiro antes de ler o nome..." (relativo a modelo tridimensional) (V02)

"Praça dos Cientistas, certo, e no caso do áudio realmente seria bom que o áudio dissesse olha você fazendo tal caminho você vai chegar na praça dos cientistas, lá estarão as estátuas... realmente essa parte tá bom" (V03)

"Não, tava muito bom, mas no caso como é que eu vou saber o que é a frente e atrás? Nessa coisinha?" (relativo a modelo tridimensional) (V03)

"Mas flagelo... tinha que ter uma maneira de falar..." (relativo a modelo tridimensional) (V03)

A alta incidência nessa categoria era esperada, pois, parte dos visitantes convidados é frequentadora de espaços museais e possui amplo repertório para avaliação de materiais desenvolvidos para cegos e pessoas com baixa visão. Mas é possível supor que, ao se tratar da percepção através do tato concomitante à da audição, as falas estratégicas possibilitem uma organização mental, ao colocarem em ordem os diferentes passos (as diferentes ações cognitivas) importantes na construção de uma representação mental. Ao explicitar como o áudio complementa ou contradiz a percepção tátil, o visitante cria suas próprias possibilidades de compreensão do material.

Nesse sentido, é relevante ressaltar a importância do áudio-guia na organização estrutural do pensamento teórico. A análise dos dados obtidos sugere que o texto oral é fundamental ao oferecer elementos para a resolução de problemas e criação de representações visuais, como relatado por Smothers e Goldston (2010) e observado no trecho a seguir:

\begin{abstract}
"Aqui tá até respondida aquela minha colocação sobre as bactérias... elas podem vir assim, né, fechadinha e o áudio poderia falar: essa é a forma original dela externa ou é a forma original por fora, é uma, explica que ela tá fechada e que a forma dela é essa mas que é possível a gente abrir, poderia ser desse jeito" (V03)
\end{abstract}

A segunda categoria mais frequente foi a "Perceptiva de Caracterização" (10,8\%), representada por falas em que os visitantes descreviam propriedades específicas dos objetos tridimensionais (dimensões e formas) e em casos que estabeleciam comparações com algo já visualizado mentalmente. Alguns exemplos desta categoria são citados a seguir:

"Mas o tamanho dela, a espessura essas ranhuras aqui ó...”(V01)

"Parece uma célula." (V01)

"Tá... como eu te falei né, eu tenho Braille, mais aqui... e 
o que é isso que parece uma panela aqui... (risos) aqui é o telhado, é o teto" (V02)

"Gozado né, a gente pega a figura de um livro, bom..tem ...ahn... tá bem proporcional né, essa quantidade de fimbrias, tá bem proporcional." (V02)

"É... redondinho assim.. aí caramba..." (V02)

"Então eu gravei que ela com certeza não vai ser do mesmo material, mas ela deve ter esses cílios mesmos pra ajudar a se fixar, né, imagino..." (V03)

"Isso aqui parecem ser estátuas" (V03)

Para as pessoas cegas e de baixa visão, a interação está ligada ao acesso físico aos objetos e às informações sobre eles. Assim, a comunicação dos conteúdos dos museus é realizada facilitando-se a acessibilidade física dos objetos por meio do tato. Entretanto, a pessoa pode encontrar dificuldades na identificação tátil quando os objetos diferem em tamanho, tipo ou profundidade já que a informação complementar depende de fatores pessoais, das características físicas do próprio objeto e dos sinais de referência que o acompanham interferindo na compreensão dos mesmos (MILLAR, 1997).

Outras duas categorias mais frequentemente encontradas a partir das gravações foram "Afetiva de Prazer" (10,2\%) e "Perceptiva de Identificação" (8,6\%). A alta incidência das conversas afetivas de prazer era desejada pela equipe executora, pois, conforme Hernandez Sanz (1993), com o uso das palavras, uma pessoa com deficiência visual pode formar uma imagem mental principalmente se esse estímulo atingir também aspectos emocionais. Assim, ao se optar por materiais de melhor qualidade, contratação de profissionais habilitados para a confecção dos modelos, por detalhamento cuidadoso de todo 0 processo, esperava-se que houvesse uma boa aceitação pelo público. Alguns exemplos podem ser citados:

"Legal, esse aqui também tá bem, bem explicativo" (V01)

"A tá ahã (concordando). A maquete tá muito boa, viu?!"(V02)

"Muito bem feito, hein, que material é feito, resina?" (V02)

"Da hora, da hora, esse dos fungos!" (V03)

Um outro dado que fornece subsídios para a compreensão de que áudio e materiais para tato devem estar bem articulados foi a menor incidência da categoria "Perceptiva de Identificação". Pesquisas anteriores também realizadas em ambientes museais, como a de Allen (2002) e Garcia (2006), obtiveram maior incidência da categoria perceptiva. Entretanto, estas pesquisas foram desenvolvidas com pessoas videntes, que comumente utilizam a identificação de aparatos para a comunicação intragrupo. No presente estudo de caso (MicroToque), em geral, as falas identificatórias referiam-se a "confirmações" da representação mental construída a partir da interação com essas ferramentas: 
"Aqui seria a entrada, e aqui, na, na, a esquerda, seria o auditório que ele fala..." (V02)

"Uma lojinha de souvenir, é isso?" (V02)

"Isso aqui seria no caso a tenda uniforme que ele fala? "(V03)

Outras categorias elaboradas por Allen (2002) também foram encontradas nas entrevistas realizadas, embora com menor frequência, e estão listadas na Tabela 1.

\begin{tabular}{|c|c|c|}
\hline Categoria conversacional & $\begin{array}{c}\text { № de } \\
\text { conversas }\end{array}$ & Exemplos \\
\hline Perceptiva de Citação & 26 & $\begin{array}{l}\text { "Bactéria es...cheri.ah tem um nome } \\
\text { que só vocês conseguem falar, né!" }\end{array}$ \\
\hline Conceitual de Inferência Simples & 23 & $\begin{array}{l}\text { "Isso aqui é permanente né?! Essa } \\
\text { praça?" }\end{array}$ \\
\hline Perceptiva de Nomeação & 22 & Só é um vírus, é um vírus. \\
\hline Conectiva Intraexibição & 20 & $\begin{array}{l}\text { "Então eu gravei que ela com certeza } \\
\text { não vai ser do mesmo material, mas ela } \\
\text { deve ter esses cilios mesmos pra ajudar } \\
\text { a se fixar, né?! Imagino." }\end{array}$ \\
\hline Conceitual de Inferência Complexa & 18 & $\begin{array}{l}\text { "E no caso o áudio também fala que elas } \\
\text { vivem dentro da gente, mas só faltou } \\
\text { aquela questão de como ela chega } \\
\text { dentro da gente, se a gente produz isso } \\
\text { ou não, faltou só isso." }\end{array}$ \\
\hline Conceitual de Previsão & 16 & $\begin{array}{l}\text { "Acho, que vírus é esse mesmo, bom } \\
\text { não é o da AIDS não, né?" }\end{array}$ \\
\hline Conceitual de Metacognição & 15 & $\begin{array}{l}\text { "Aqui tá até respondida aquela minha } \\
\text { colocação sobre as bactérias..." }\end{array}$ \\
\hline Conectiva com o Conhecimento & 15 & $\begin{array}{l}\text { "Por isso que eu tava tentando ver se } \\
\text { tem um núcleo, alguma coisa, mas com } \\
\text { essa estrutura aqui ó, não tá com cara } \\
\text { de ser célula, né?!" }\end{array}$ \\
\hline Estratégica de Metaperformance & 15 & $\begin{array}{l}\text { "Como é um Penicilium notatum eu vou } \\
\text { saber mais ou menos descrever." }\end{array}$ \\
\hline Conectiva com a Vida & 8 & $\begin{array}{l}\text { "Ah, isso aqui é... não sei como que é } \\
\text { o... Ah! isso aqui eu tenho certeza que } \\
\text { é... Á caramba!A nossa mãe falava } \\
\text { tanto isso aqui." }\end{array}$ \\
\hline Afetiva de Desprazer & 6 & $\begin{array}{l}\text { "Então... risos...ruim é esses nomes } \\
\text { esquisitos que é...esses nomes } \\
\text { científicos." }\end{array}$ \\
\hline
\end{tabular}

Tabela 1. Categorias conversacionais com menor incidência nas falas dos visitantes no Programa para Deficientes Visuais. 


\section{Considerações finais}

Os dados apresentados aqui fornecem subsídios para a discussão sobre diferentes possibilidades de estratégias comunicacionais e educativas que maximizam a interação entre visitantes com deficiência visual e discursos expositivos de museus de ciências, proporcionando um maior desenvolvimento de vestígios de aprendizagem e possibilitando diversos tipos de elaborações conversacionais. Não queremos, com isso, afirmar que um tipo específico de estratégica educativa leve a determinados tipos de conversas, mas sim que a multiplicidade e a qualidade das ações podem propiciar momentos interativos distintos que promovam um ou outro tipo de elaboração conversacional com maior frequência.

Em relação aos materiais desenvolvidos para deficientes visuais, a junção das ferramentas tátil e auditiva foi extremamente importante para a construção e a compreensão de conceitos, ao facilitar a organização estrutural do pensamento teórico. Além disso, o uso de materiais de boa qualidade, a escoIha por profissionais especializados e o rigor na apresentação dos diferentes saberes envolvidos contribuíram para a formação de imagens mentais.

A manipulação de modelos tridimensionais favoreceu a habilidade de caracterização de objetos entre os deficientes visuais, o que é pouco encontrado entre videntes (GARCIA, 2006; SAPIRAS, 2007). Assim, caso educadores de museus tenham interesse em desenvolver a habilidade de caracterizar objetos entre o público vidente (considerando-se que o desenvolvimento das habilidades de observação e caracterização é desejado no processo de alfabetização científica), é possível que a inserção de materiais para toque em suas ações represente uma boa estratégia educativa. . A inserção de materiais auditivos e para toque poderia propiciar ainda o desenvolvimento de conversas afetivas de prazer.

Em comparação com resultados de pesquisas anteriores semelhantes a essa com o público vidente (GARCIA, 2006; SAPIRAS, 2007), foi observado que videntes e não-videntes utilizam-se das categorias conversacionais de forma diferenciada. Enquanto os primeiros, por exemplo, utilizam a identificação de aparatos para a comunicação intragrupo, os segundos a utilizam para a confirmação de suas idéias, em uma perspectiva inicialmente individual. É importante, portanto, que essas diferenças sejam consideradas na elaboração de exposições ou outras mídias.

Vale ressaltar que conversas interpretativas conceituais são ferramentas comunicacionais importantes dentro de um grupo social em visita a exposições, promovendo a aproximação entre os repertórios culturais científicos daqueles mais experientes e de novatos. Notou-se que o discurso expresso na ação educativa analisada permitiu diferentes manifestações cognitivas por seus visitantes, em diferentes graus de complexidade, com a presença de conversas conceituais de inferência simples e complexa, porém em frequências relativa- 
Alessandra Fernandes Bizerra - Juliana Bettini Verdiani Cizauskas Glaucia Colli Inglez - Milene Tino de Franco

mente baixas. Além disso, as conversas conectivas dentro de um mesmo grupo social, que fortalecem valores e concepções compartilhados entre seus membros, também se mostraram pouco presentes. Ações educativas que propiciem a elaboração destes tipos de conversas, como a presença de um mediador que estimule reflexões dentro do grupo ou áudios dialógicos que promovam o uso de memórias pessoais, são importantes para que um fortalecimento da alfabetização científica possa realmente ocorrer.

Sugere-se que, ao elaborar novas ações educativas, as equipes museais levantem os conhecimentos prévios de seus visitantes com deficiências visuais, em seus diferentes graus. Ao incluir essas informações em seus aparatos, é possível que se propiciem maiores frequências de conversas conectivas, como associações ou comparações de elementos encontrados na visita com algo familiar ou com conhecimentos obtidos anteriormente em outros espaços de educação formal ou não formal. Além disso, uma organização dos conteúdos científicos é necessária para o estabelecimento de conversas conceituais, simples ou complexas. A determinação de conceitos germinais, a estruturação de modelos cognitivos e o entendimento dos áudios como elementos da Zona de Desenvolvimento Proximal, em uma perspectiva vigotskiana, parecem oferecer um bom caminho a ser investigado.

É importante ressaltar que a abordagem metodológica proposta por Allen (2002) nos fornece boas dicas para uma reflexão sobre "o que" o público de museus explicita em suas conversas ao longo de uma atividade de visita. Sabemos que, entretanto, esse método de análise não é propício quando a intenção do pesquisador é compreender "como" se dá o processo de aprendizagem nesses espaços. Para um entendimento das estratégias utilizadas pelos visitantes na apropriação desses "o quê" e "quanto", outras ferramentas de análise tornam-se necessárias.

\section{Referências}

ALLEN, S. Looking for Learning in Visitor Talk: A Methodological Exploration. In: LEINHARDT, G.; CROWLEY, K.; KNUTSON, K. (eds.). Learning Conversations in Museums. Mahwah: Lawrence Erlbaum, 2002. p. 259-303.

BANNON, L. Activity Theory. 1997. Disponível em: <http://wwwsv.cict.fr/cotcos/pjs/ TheoreticalApproaches/Actvity/ActivitypaperBannon.htm. Acessado em julho 2011.

CONSUEGRA CANO, B. El acceso al patrimonio historico de las personas ciegas y deficientes visuales. Madrid: ONCE. 2002.

FALK, J.; DIERKING, L. Learning from Museums: Visitors Experiences and the Making of Meaning. Walnut Creek: Altamira Press. 2000. 272 p.

GARCIA, V. O Processo de ensino-aprendizagem no Zôo de Sorocaba: análise da atividade de educativa visita orientada a partir dos objetos biológicos. 2006. 224 fls. Dissertação (Mestrado em Educação) - Faculdade de Educação, Universidade de São Paulo, 2006. 
HERNÁNDEZ SANZ, J. Los museos y los sistemas audiovisuales. En: IX Jornadas Estatales DEAC-Museos La exposición, 1993. p. 273-281.

MILLAR, S. La comprensión y la representación del espacio: teoría y evidencia a partir de estudios con niños ciegos y videntes. Madrid: ONCE; Sección de Educación, 1997.

PINO, A. As marcas do humano - às origens da constituição cultural da criança na perspective de Lev. S. Vigotski. São Paulo: Cortez, 2005. 304p.

RIBEIRO, M.G. Inclusão Social em Museus. In: X Reunión de la RED de Popularización de la Ciência y la Tecnología em America Latina y el caribe (RED POP - UNESCO) y IV Taller "Ciência, Comunicación y Sociedad. San José, Costa Rica, 2007. Disponível em http://www.cientec.or.cr/pop/2007/ BR-MariaRibeiro.pdf. Acessado em março de 2011.

SÁPIRAS, A. Aprendizagem em Museus: uma análise das visitas escolares no Museu Biológico do Instituto Butantan. 2007. 155 fls. Dissertação (Mestrado em Educação) - Faculdade de Educação, Universidade de São Paulo. 2007.

SMOTHERS, S. M.; GOLDSTON, M. J. Atoms, elements, molecules, and matter: An investigation into the congenitally blind adolescents' conceptual frameworks on the nature of matter. Science Education, New York, v. 94, n. 3, mai. p. 448477, 2010.

VYGOTSKI, L. S. El niño ciego. In: VYGOTSKI, L. S. Obras Escogidas V: fundamentos de defectologia. Madrid: Visor, 1997. p. 99-113.

\section{Agradecimentos}

As autoras agradecem o apoio da Fundação de Amparo à Pesquisa do Estado de São Paulo (FAPESP), Fundação Vitae, Fundação Dorina Nowill para Cegos e Laramara - Associação Brasileira de Assistência ao Deficiente Visual.

Correspondência

Glaucia Colli Inglez - Museu de Microbiologia, Instituto Butantan, Av. Vital Brasil, 1500, CEP: 05503-900 - Butantã, São Paulo, Brasil.

E-mail: lebizerra@gmail.com - jumareazul@yahoo.com.br - glaucia@butantan.gov.br milene@butantan.gov.br

Recebido em 23 de novembro de 2011

Aprovado em 09 de fevereiro de 2012 